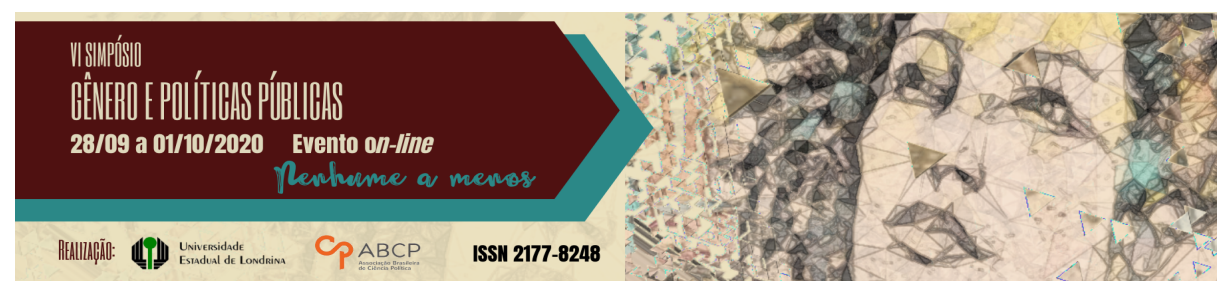

\title{
Reconhecimento do enfrentamento à violência: feministas, mulheres e delegacias
}

\author{
Juliana Lencina da Silva ${ }^{1}$
}

\begin{abstract}
Resumo
O presente trabalho analisa a relação do reconhecimento de identidade de gênero com às práticas de combate à violência contra mulheres. Para tanto, articulam-se relações entre o surgimento de delegacias especializadas em atendimento à mulher e o movimento feminista e de mulheres no Brasil, sobretudo pelas lutas de reconhecimento da criminalização da violência contra a mulher pelo Estado brasileiro. $O$ trabalho examina a idealização, a organização e o funcionamento da primeira delegacia especializada no país, na cidade de São Paulo - SP. A análise é realizada através de teoria sociológica das identidades, da ação social e das relações de gênero, passando pela discussão sobre a autoidentificação e questionamento do reconhecimento de agentes policiais femininas e vítimas.
\end{abstract}

Palavras-chaves: teoria do reconhecimento; violência contra mulher; movimento feminista.

\section{Recognition of combating violence: feminists, women and police stations}

\begin{abstract}
This paper analyzes the relations between the recognition of gender identity and practices to combat violence against women. To this end, relations are

${ }^{1}$ Mestranda em Sociologia (PPGS-UFF), e Bacharel em Sociologia pela Universidade Federal Fluminense (2018). Integrante do LabGen - Laboratório de estudos de gênero e interseccionalidade (PPGSUFF), e do LSD Laboratório de Sociologia Digital (PPGSUFF). E-mail: julianalencina@id.uff.br.
\end{abstract}

GT 17 - Policiamento Plural e Dinâmicas de Gênero 
articulated between the emergence of police stations specialized in assisting women and the feminist and women's movement in Brazil, mainly due to the struggles to recognize the criminalization of violence against women by the Brazilian State. The paper examines the idealization, organization and functioning of the first specialized police station in the country, in São PauloSP. The analysis is carried out through a sociological theory of identities, social action and gender relations, going through the discussion about selfidentification and questioning the recognition of female police officers and victims.

Keywords: recognition theory; violence against women; feminist movement.

\section{Introdução}

Após algumas conquistas das mulheres brasileiras na vida pública como o direito ao voto e reconhecimento do Estado como problema de segurança pública pela violência praticada contra elas em espaços privados, há um impasse sobre a representação de mulheres, sobretudo sobre em espaços dos setores públicos. A lei estadual $\mathrm{n}^{\mathrm{0}} 1882 / 16$ do Rio de Janeiro indica que $20 \%$ dos cargos de agentes das delegacias de atendimento à mulher (DEAM) sejam preenchidos para mulheres. Há o pressuposto de que a representação de mulheres em cargos das Delegacias é suficiente para cumprir necessidades das vítimas, pelo reconhecimento da identidade de gênero. É pela observação da implementação dessa lei que se pode analisar alguns indícios das problemáticas da representação de identidade nesse caso impactando nas dinâmicas cotidianas de combate à violência contra mulher. Para tanto, é observado o impacto das primeiras delegacias especializadas em crimes contra mulher no Brasil, em especial na cidade de São Paulo - SP se utilizando de entrevistas e análises de outros trabalhos já realizados nesse período identificando assim, o reconhecimento de sujeitos na relação de atendimento entre agentes e vítimas de modo a repensar esse pressuposto. Para tanto, aborda-se o reconhecimento da violência perante o Estado, pois é a partir disso que se pode conceituar a violência de gênero e observar como ela é percebida pela sociedade já que nesse momento deixa de ser problema 
da esfera privada e se torna um problema de segurança pública. Logo depois, descreve-se a desigualdade de gênero a partir das determinações da diferença entre vida pública e privada, passando a se observar as relações de poder de gênero na medida que os direitos relacionados a esses dois espaços, sobretudo pelo trabalho. E por fim, discute-se o próprio reconhecimento da violência na delegacia especializada através da percepção da violência por agentes e outros atores pelo reconhecimento de identidade.

\section{Reconhecimento da violência e o Estado}

As ocorrências de crimes de violência contra mulher no Brasil têm se tornado um cenário de um grande laboratório de pesquisas para o tema. Elas indicam que essas ocorrências de violência contra o gênero crescem paralelamente com a desigualdade social do país, pois estão diretamente relacionadas. Todavia, a lógica da incidência entre desigualdade-violência não é tão simples - até mesmo por alguns autores afirmarem que a violência está nas relações de poder pelo estabelecimento de determinadas desigualdades. A questão é que essa lógica não está na violência praticada em si, que poderia ser explicada por outros termos e discussões e pela estrutura de desigualdade entre gêneros que está presente no eixo formador da própria Modernidade, mas em medidas que o Estado introduz para punição e conscientização dessas práticas.

O Estado aqui tem papel como atuante geralmente na defesa de direitos das mulheres, ou seja, a desigualdade está muito mais imbricada à violência quando localizada em pontos onde é possível observar como a sociedade lida com a dominação dos corpos das mulheres. Onde, nessa situação, as mulheres em relações aos homens aparecem como exercício de resistência, enquanto homens exercem o poder pelo dispositivo do discurso da sexualidade, ou seja, os homens se estendem a um objetivo estratégico a partir de uma racionalidade 
Moderna em forma de saber e constituem assim a dominação (Foucault, 1980).

Mas não somente se trata da relação entre homens e mulheres. Circunstâncias de classe social e raça no interior do gênero se tornam também variáveis que devem ser consideradas para análise, não somente para aspectos econômicos, mas os culturais incluindo a acessibilidade das mulheres aos seus direitos e a possibilidade do exercício deles. Algo que é examinado a partir da abordagem acerca do lugar da mulher na vida pública.

A discussão sobre a legitimidade da violência acometida contra a mulher, é complexificada quando analisada a partir da classe. Numa entrevista realizada numa feira de livro em Frankfurt em 2013 por Christian Grünnagel Doris Wieser (2015), publicado no Dossiê: 'Nós somos machistas' descreve as impressões de escritores brasileiros sobre masculinidades e machismo partindo da abordagem teórica de Connell ${ }^{2}$ e seu conceito de masculinidades. Em uma entrevista feita aos autores sobre a dinâmica e configurações do cotidiano brasileiro em 'O Brasil é um país extremamente machista' (2015), respondem sobre violência doméstica nas diferenças regionais e de classe do país:

a violência doméstica na classe média alta é tão alta como na classe média baixa, com um detalhe muito interessante: na classe média baixa, quando um homem agride uma mulher, ela faz escândalo, chama, berra, grita e a gente acorda. Na classe média alta, não! Porque pega mal, porque é uma vergonha pública. Eu acho que dentro da classe média alta são muito mais hipócritas porque as mulheres são ofendidas e agredidas, mas vão muito menos às delegacias denunciar os homens, inclusive porque, muitas vezes, são casamentos que tem muito

\footnotetext{
2 Raewyn Connell é uma socióloga australiana que muito contribui ao campo de estudos de masculinidades. Segundo sua teoria as masculinidades estariam divididas em quatro tipos ideais que não estão ligados diretamente à identidade: hegemônica; subordinada; cúmplice e marginal. Ao depender da relação e da situação o sujeito que por sua vez, também ao depender da corporeidade e capitais que possui pode manifestar o tipo muitas vezes como forma de dominação, mas não necessariamente.
} 
dinheiro envolvido, e portanto, a separação envolve muito mais coisas do que entre pobres, em que a separação se dá, digamos, apenas "entre corpos". A violência doméstica na classe média alta é tão grande quanto na classe baixa (GRUNNAGEL; WIESER, 2015. p. 384).

Também numa entrevista para uma pesquisa do ‘Observatório da Mulher contra violência' 3 do DataSenado, a procuradora da Mulher na cidade de Santa Maria no estado do Rio Grande do Sul indica as diferenças entre classes durante a inibição da denúncia:

a dependência econômica atinge a classe mais baixa geralmente não tem onde morar, isso inibe mais. Mas a mulher de uma classe social alta, a vergonha pode ser um fator que impeça mais, pela questão de estar mais preocupada com o que a sociedade, família e amigos vão pensar. (DATASENADO, 2018. p.18).

No cenário brasileiro, a utilização do termo 'machismo' está sempre sendo discutida entre categoria nativa e analítica, assim como quase toda a américa latina, onde o machismo é visto como algo utilitário no ideal de virilidade. Portanto, torna-se notável que agressores de crimes de violência contra mulheres estão em uma estrutura identificada como patriarcal agindo de forma naturalizada e dentro de uma hegemonia de dominação independente das classes:

Embora alguns defendam que um comportamento "machista" depende de uma falta de cultura e educação [...] outros sublinham a presença e continuidade de práticas machistas em todas as classes da sociedade brasileira atual, com a única mas importante - diferença de que o machismo é bem visível e "evidente" nas classes baixas, enquanto nas classes médias e altas está mais camuflado e reduzido

\footnotetext{
3 Aprofundando o olhar sobre o enfrentamento da violência contra mulheres do Instituto de Pesquisa DataSenado/Secretaria de Transparência. 2018. Pode ser acessado em: https:// www12.senado.leg.br/institucional/datasenado/arquivos/conhecer-direitose-ter-rede-de-apoio-saopontos-de-partida-para-denunciar-agressao-e-interromperciclo-de-violencia
} 
à intimidade do casal (GRUNNAGEL; WIESER, 2015. p. 384).

Considera-se, assim, o reconhecimento da violência dirigida às mulheres como crime real, porém como uma prática vexatória para as classes mais altas, justificada também pela possibilidade da perda de bens e patrimônio da família. As classes mais baixas, por já estarem em posições marginalizadas têm maiores propulsões de reivindicar os seus direitos pois não têm o acúmulo material. Porém, essas relações não podem ser somente observadas pela possibilidade de perda material. $\mathrm{O}$ caráter simbólico também é bastante presente.

É visto que nas classes mais altas há uma tentativa de todo modo a escapar dos 'escândalos' no interior da família, de modo a não tornarem públicos. Esse comportamento remete a uma configuração de sociedade pré moderna e religiosa, assim como Foucault cita em sua tese acerca do Biopoder. O poder que precede o Moderno coloca questões da dinâmica da família ao problema privado e confessional. A modernidade com a criação do Estado, organiza alguns dos problemas que estavam antes no privado levando ao público por campos de saber.

\section{Movimento de mulheres e a vida pública}

A conquista do direito ao voto das mulheres brasileiras em 1932 é um divisor de águas na participação da mulher na vida pública e privada, pois é com o acesso ao voto as mulheres estariam pela primeira vez exercendo seu poder de decisão na vida pública, de formas a serem reconhecidas pelo Estado. Essa conquista, assim como todas as outras de grupos minoritários, foi consequência de intensas lutas e da organização de mulheres pela reivindicação de direitos antes mesmo da proclamação da República, algo que ganhou força pela onda de ideais de lutas igualitárias entre homens e mulheres ao redor do mundo no Século XX.

O Equador se tornou o primeiro país na América latina a conceder o sufrágio feminino no ano de 1929 e, também serviu de 
inspiração para os outros países nas Américas. Porém, com a onda de conservadorismo em meados do século $X X$ e implementação de ditaduras, esse progresso freou. Apesar das mulheres terem conquistado o direito ao voto, nem todas tinham a possibilidade de votar - apenas mulheres casadas e com autorização dos maridos, e solteiras que tinham renda própria e não dependessem financeiramente da família. Com o estabelecimento de governo autoritários sobretudo na América latina, a democracia foi suspensa. O Movimento Feminino pela Anistia (MFPA) idealizado por Therezinha Zerbini, teve importância não somente como organização de mulheres mas como organização a favor da democratização do país, era um movimento de classe média com apoio religioso que segundo a própria Zerbini, os militares na época não levaram muito a sério por se tratar de mulheres reunidas e logo apresentariam algum tipo de ameaça à ditadura Em 1985, algo essencial à reconstrução de um Estado democrático foi a organização de mulheres reivindicando participação política e reconhecimento de direitos, como no caso da violência contra mulheres. Não há possibilidade de descrever o período de redemocratização no país sem levar em consideração as lutas de mulheres nesse período.

A civilização como bem definida por Engels (1984), determina que homens possuem a importância na linhagem, pois estão atrelados a herança dos bens, à acumulação de riquezas geradas durante as gerações. Logo seus filhos tornam-se parte do gens dos homens, e a mulher passa a desempenhar aqui o papel de reprodutora. Nesse tipo de associação o rompimento da relação se torna decisão do homem e a infidelidade também. Esse raciocínio leva a mulher a uma condição de seguir fielmente ao casamento, já que essa deve ser geradora dos filhos do homem que está casada, e apenas dele. Apesar dessas transformações não serem bem aceitas pelas mulheres ${ }^{4}$. A submissão da

4 Na 'A origem da família, da propriedade privada e do Estado', o autor mostra
episódios de resistência feminina quanto a fidelidade no casamento no momento no
qual cita uma medida que Napoleão teve que intervir sobre a moralidade dos
casamentos. Institui-se no seu Código que as crianças nascidas dentro de um casamento 
mulher na idade Moderna para Engels, estaria justificada na relação do homem com a propriedade privada. Para a teoria marxista, as sociedades ditas como primitivas, homem e mulher teriam papéis distintos na organização social.

O autor vai além em sua análise e afirma que essas novas relações de família se tornam as primeiras que indicam as desigualdades de um sistema capitalista em formação. Há um embate de natureza sexual que oprime um dos sexos para que se torne possível a ascensão do outro:

A monogamia foi um grande progresso histórico, mas, ao mesmo tempo, iniciou, juntamente com a escravidão e as riquezas privadas, aquele período, que dura até nossos dias [...] o bem-estar e o desenvolvimento de uns se verificam às custas da dor e da repressão de outros (1984, p. 70).

A problemática da homogeneização da classe trabalhadora traz consigo uma resposta que não é tratada no cotidiano das relações entre trabalhadores em Marx. O marxismo aqui se apresenta como uma teoria totalizante, de estruturas formadas por relações de exploração, e que consequentemente dividem a sociedade em classes. E segundo as autoras, o problema está em ser totalizante ao ponto de não representar grupos distintos dentro das próprias classes.

como contraponto à teoria marxista-leninista de que mulheres têm menos poder social do que os homens no capitalismo porque, como 'donas de casa', estão fora das relações capitalistas; uma visão cuja tradução política seria a emancipação das mulheres por meio do trabalho assalariado [...] para muitas feministas, isso era inaceitável. (FEDERICI, 2017. p. 11).

As mulheres em O Capital não tem existência como sexo social mas fazem parte com outras categorias sociais do exército de reserva industrial[...]a

teriam como pai o marido da esposa, a paternidade passava a ser uma obrigação moral das famílias já que o adultério das esposas era inevitável. 
exploração conceito chave do marxismo e base da relação antagônica entre as classes era fundamentalmente insuficiente para mostrar a opressão sofrida pela mulher quanto as relações homem/mulher no seio da sociedade (HIRATA; KERGOAT, 1994. p. 94)

Das objeções que Marx traz ao movimento feminista quando aborda gênero segundo sua definição de classe, a maior estaria na afirmação do autor que o capitalismo emancipou as mulheres para a vida pública ${ }^{5}$. É nesse momento que Federici (2017) dá destaque à importância de se pensar na história das mulheres não somente a partir da modernidade como um período superado e emergente do feudalismo. Mas sim pela necessidade de se enxergar que as relações que se davam nesse contexto de passagem estão diretamente ligadas à divisão sexual do trabalho.

Há um crescimento de um segmento de produção teórica e de trabalhos a partir da metade do século que tratam sobre mudanças mercadológicas referentes a gênero. Todavia, uma grande parte dessas produções procedem sobre as novas formas de relação das mulheres num sentido mercadológico. Quase nenhum revê o trabalho que já era realizado por essas mulheres quando elas saem de casa. Momento que mais uma vez é legitimando pelo não reconhecimento do trabalho doméstico como de fato um trabalho. À maneira que são analisadas camadas de interseccionalidade pelas relações de trabalho são vistas trajetórias bastante diferentes entre mulheres brancas e negras no Brasil. Enquanto mulheres brancas defendiam seus direitos de estudar e trabalhar, as mulheres negras eram as que cuidavam dos seus filhos e da casa na ausência das mulheres brancas. A história das mulheres no

\footnotetext{
5 Ele não aborda aqui sobre as opressões sofridas pelas mulheres em diversos âmbitos sociais. E afirma que capitalismo teria emancipado a mulher no sentido de não ser mais oprimida. Porém, seu real significado está no novo arranjo social que a mulher é inserida na vida pública como parte do proletariado. Ou seja, para Marx, a mulher se torna também força de trabalho, e é daí então que se pode discutir todas as outras opressões do capitalismo. Não considerando as diferenças sexuais e como elas implicam nas posições e logo em opressões. Pensando apenas nas diferenças das relações a partir da classe econômica.
} 
trabalho do espaço privado e a tentativa de libertação dele no Brasil sempre se passará por questões raciais.

Fator que não pode ser desconsiderado é que essas lutas por direitos se passam no interior de um país colonizado. E como já foi colocado, elas correspondem a um grupo de mais da metade da população nacional. Combinando esses e outros fatores, posicionam-se mulheres numa pluralidade de outros grupos e experiências que chamam atenção da academia. "O grande ativismo feminista, a luta contra o racismo e por novas identidades foram responsáveis pelo avanço de novas formulações teóricas" (Melo; Thomé. 2018. p.18).

No caso brasileiro, e talvez expandindo para quase todo caso latino-americano, uma parte considerável de mulheres negras e indígenas já trabalham fora do próprio ambiente privado há muito mais tempo do que essa constatação de crescimento do trabalho remunerado da mulher. Trabalhando muitas vezes nas casas de outras mulheres, como por exemplo, as empregadas domésticas, babás e cozinheiras. Novamente cabe evidenciar a necessidade de se pensar relações de gênero sempre a partir de outras variáveis para indicar as posições sociais.

\section{O reconhecimento e as delegacias}

Após a criação das delegacias especializadas ${ }^{6}$ em atendimento de violência contra mulher, surge um novo problema: o treinamento dos agentes policiais que não estavam até então familiarizados com essa nova prática de abordagem. compreensão de identidades da violência contra mulher legitimada pela primeira vez perante o Estado burocrático. Dado o novo problema nas delegacias, o estado de São Paulo na década de 1980 resolve agir dispondo de oficiais mulheres no

\footnotetext{
${ }^{6}$ Em 1985, em São Paulo-SP surgiu a primeira delegacia especializada de atendimento à mulher no Brasil. Surge em meio às contestações da polícia como instituição legítima até então vista com desconfiança por grande parte da população. Pois a polícia militar foi um aparato utilizado pelo poder público na ditadura.
} 
quadro de policiais das delegacias especializadas da mulher partindo do pressuposto de que a percepção pela identidade de gênero bastaria na comunicação entre vítima e autoridade. Porém não é levado em consideração toda a história sociocultural do Brasil em ser um país machista e conservador que até pouco tempo não tornava como algo público o problema de violência contra mulheres.

Seguindo os estudos de MacDowell Santos (2015), é possível constatar que há um aumento de denúncias ${ }^{7}$ de vítimas logo após a criação das delegacias de mulheres no Estado de São Paulo no ano de 1985 e 1986. A implementação teve sucesso, atingiu parte do que se esperava como proposta ao atendimento, logo foram criadas outras delegacias, de 1985 até 1990 se contabilizaram 58 delegacias especializadas. A implementação cresce também pela demanda por direitos, devido também aos processos de conscientização - diretamente relacionados ao movimento feminista - do crime de violência contra mulheres. Porém, indo para as análises qualitativas, a socióloga observa que os índices de conscientização das policiais mulheres não eram o mesmo constatando:

Em um primeiro momento, conheci policiais que fizeram alianças explícitas com feministas, concluindo completamente o discurso feminista sobre a violência contra as mulheres. Essa posição era predominante na década de 1980 e recuperou destaque em 1994 e novamente no período entre 1998 e 2000. Segundo, encontrei policiais que se opunham a qualquer contato com feministas e não viam a violência contra as mulheres como um crime real (SANTOS, 2004, P. 31).

De todo modo, existe uma demanda de estabelecer um quadro de agentes femininas nas dinâmicas de atendimento às vítimas. Em 1985, consta-se que pouco houve formação de capacitação de agentes

\footnotetext{
7 Dados da Folha de São Paulo que quantificam as ocorrências registradas 7.000 mulheres na única delegacia especializada, entre o ano de 1985 a 1986 a partir do mês de agosto. Sendo no ano anterior, 1984, apenas 3.000 denúncias registradas por delegacias comuns em todo o Estado. (Folha de São Paulo, 1986. Apud. Santos, 2004)
} 
para lidar com casos específicos de violência nessa nova delegacia, onde agentes homens e mulheres pouco sabiam de novas formas de lidar com a defesa e atendimento às mulheres nos casos de violência. Em 1996, é decretado pelo governo do estado de São Paulo novas atribuições às Deams, entre eles estão os crimes relacionados ao direito da criança e ao adolescente e, também crimes de aborto praticados por mulheres mesmo sem consentimento da prática, levando assim as mulheres à posição de criminosas. (Santos, 2001) O que leva às controvérsias da proposta de criação desse tipo de delegacia

Interessante notar que, por ocasião de um debate sobre a expansão das atribuições das delegacias da mulher, realizado na Assembléia Lesgilativa de São Paulo no início de 1996, tive a oportunidade de observar que muitas delegadas titulares de delegacias da mulher, temendo a extinção de tais delegacias, defenderam a farta ampliação de sua competência, inclusive com o acréscimo de crimes de aborto e infanticídio (SANTOS, 2001).

Para Santos, a delegacia é a forma concreta mais próxima que existe de se combater a violência de gênero, pois a punição e serviços são colocados de maneira a estarem disponíveis publicamente às vítimas, porém a autora observa durante seu tempo de pesquisa, que não houveram muitas formas de capacitação específica de agentes, delegadas, escrivães, atendentes e outros funcionários que lidam direta e indiretamente com o atendimento e acolhimento de vítimas. Essa falta reflete na dinâmica das delegacias desde em quase todos os processos de criminalização da ocorrência. Segundo a autora, as formas de capacitação de agentes e outros profissionais do quadro de funcionários dessas delegacias é feita sobretudo por meio de cursos sobre o tema oferecidos de forma externa a própria Academia de Polícia, realizado pela iniciativa de organizações sociais locais e outras políticas públicas coordenadas por mulheres externas à polícia (Santos, 2001). A abordagem que compreende o comportamento entre vítima e autoridade nesse caso, está na teoria do reconhecimento bastante elucidada por Axel Honneth, e Nancy Fraser. A legitimidade do 
sofrimento de uma certa minoria social - no caso as mulheres que sofrem violência - é institucionalizada pelo Estado. Este por sua vez, organiza formas de coibir ânsias das vítimas, porém, mesmo com a disposição de leis e medidas não há percepção por parte dos agentes do Estado o que dificulta a justiça.

A 'experiência da dominação' em Fraser é colocada como uma das categorias de análise para se chegar na identidade do sujeito. Segundo ela, só é possível ter a percepção de injustiça quando alguém que carrega aquela marca social, no caso ser mulher, já experimentou em algum momento episódios de opressão masculina durante a vida e reivindicou esse acontecimento "não haver luta contra a dominação não implica a inexistência de dominação, porém, para que se construa a noção de justiça como motor das demandas, devem estar presentes as condições de emergência da experiência da dominação" (Pinto, 2016. p. 3). De todo modo, o que a teoria do reconhecimento consegue propor metodologicamente entre a percepção de agentes, delegadas e vítimas é que nem sempre haverá algum tipo de reconhecimento apenas pela identidade de gênero, outros marcadores de identidade acabam sendo mais pertinentes em determinadas situações. Também deve-se apoiar essa compreensão através da dinâmica do interior de um poder institucional do Estado, no caso a polícia, onde o questionamento da punição e suas formas simbólicas devem ser colocadas também em análise passando pelos marcadores que forem selecionados.

\section{Considerações}

Para fechar o raciocínio sobre a percepção de identidades e violência pelo reconhecimento do Estado, conclui-se o seguinte ponto: a atribuição de cargos às mulheres nas delegacias especializadas parte do pressuposto que elas estariam mais capacitadas às funções que lidam com casos de violência apenas por serem mulheres. Desconsiderando todos os outros marcadores que definem a identidade de uma mulher. Porém na prática, indicada por Santos (2004), foi visto que grande parte 
das agentes femininas não se identificava com as vítimas, nem sequer considerava a violência sofrida um crime que deve ser levado ao poder ao poder público.

Foi visto que a identidade a partir das questões de gênero por parte das agentes femininas não são suficientes para a identificação e reconhecimento dos problemas enfrentados pelas vítimas. Foram apontadas questões sobre interseccionalidade e autoidentificação dentro dessas questões. Indica-se o treinamento e recursos da polícia para capacitação do atendimento e uma rede mais especializada ao atendimento e acolhimento de vítimas de violência deve ser levado em consideração para a eficácia, e que apenas a eleição de policiais e delegadas femininas para o trabalho não é o suficiente já que esses sujeitos não estão fora da rede de dominação masculina nos espaços públicos.

Ainda há muita luta, e sem dúvidas o movimento feminista atuou de forma a modificar as práticas e possibilitou a discussão para que direitos fossem conquistados pelas mulheres que pode ser indicado nessa temática pela conscientização ao longo dos anos onde o crime de violência contra mulher passa a ser um crime 'real' não só pelo Estado também pelas vítimas. Agora a agenda feminista deve-se agarrar ao compromisso de apontar as falhas desse sistema de serviços prestados às mulheres brasileiras entregando pautas, sobretudo o da ocupação das mulheres em espaços públicos para que se inclua na rede de comunicação dos serviços prestados pelo Estado, dando atenção à representação de mulheres nesses espaços, amenizando as configurações de uma sociedade posicionada em relações patriarcais, e que assim possam desenvolver novas estratégias efetivas e estabelecer novas políticas para uma vida mais justa.

\section{Referências}

BRINGEL, Breno. Com, contra e para além de Charles Tilly: mudanças teóricas no estudo das ações coletivas e dos movimentos sociais. 2012. 
CRENSHAW, Kimberlé. Documento para o encontro de especialistas em aspectos da discriminação racial relativos ao gênero. Revista Estudos Feministas, 2002.

DUARTE, Ana Rita Fonteles. O Movimento Feminino pela Anistia na luta contra a ditadura no Brasil: entrevista com Therezinha Zerbini. Revista Estudos Feministas, Florianópolis, v. 27, n. 1, e53564, 2019.

FEDERICI, Silvia. Calibã e a bruxa. Mulheres, corpo e acumulação primitiva. São Paulo: Editora Elefante, 2017.

FOUCAULT, Michel. História da sexualidade: a vontade de saber.3. ed. Rio de Janeiro: Graal, 1980. v. 1.

GRUNNAGEL, Christian; WIESER, Doris. O Brasil é um país extremamente machista: entrevista com Luiz Ruffato. Estud. Lit. Bras. Contemp., Brasília, n. 45, jun. 2015.

GRUNNAGEL, Christian; WIESER, Doris. "Nós somos machistas": entrevistas com escritores/as brasileiros/as. Estud. Lit. Bras. Contemp., Brasília, n. 45, jun. 2015.

HEILBORN, ML, SORJ, Bila. Estudos de gênero no Brasil. In: MICELI, S. (Org.) O que ler na ciência social brasileira (1970-1995). São Paulo: Sumaré/ANPOCS; 1999.

HIRATA, Helena. Gênero, classe e raça Interseccionalidade e consubstancialidade das relações sociais. Tempo social, São Paulo, v. 26, jun. 2014.

HONNETH, Axel. Luta pelo Reconhecimento: a gramática moral dos conflitos sociais. In: FRASER, N.; HONNETH, A. Redistribution or Recognition. Londres; New York: Ed. Verso, 2003.

KERGOAT, Danièle. Dinâmica e consubstancialidade das relações sociais. Novos Estudos Cebrap, n. 86, 2010.

MELO, Hildete Pereira de; THOMÉ, Débora. Mulheres e poder: histórias, ideias e indicadores. Rio de Janeiro: FGV Editora, 2018.

MOORE, Henrietta. Fantasias de poder e fantasias de identidade: gênero, raça e violência. Cadernos Pagu, 2000.

PASINATO, Wânia; SANTOS, Cecília M. dos. Mapeamento das delegacias da mulher no Brasil. Pagu-UNICAMP. Ceplaes. IDRC, 2008. 
PINTO, Celi Regina Jardim. O que as teorias do reconhecimento têm a dizer sobre as manifestações de rua em 2013 no Brasil. Sociedade $\mathcal{E}$ Estado, Brasília, v. 31, n. spe. 2016.

RIBEIRO, Mônica. Movimento feminista na fonte dos centros de combate à violência contra mulheres. In: Anais do I Simpósio sobre Estudos de Gênero e Políticas Públicas, Universidade Estadual de Londrina, junho de 2010.

SANTOS, Cecília MacDowell. Curto-circuito, falta de linha ou na linha? Redes de enfrentamento à violência contra mulheres em São Paulo. Revista Estudos Feministas, 23, 2015.

SANTOS, Cecília MacDowell. Delegacias da Mulher em São Paulo: percursos e percalços. In: Rede Social de Justiça e Direitos Humanos (org.). Relatório de Direitos Humanos no Brasil 2001. Rio de Janeiro: Editora Parma, 2001. p. 185-196.

SILVA, Tadeu. Documentos de identidade: Uma introdução às teorias de currículo. Belo Horizonte: Autêntica, 2005.

SIMÃO, João. Axel Honneth, Luta pelo Reconhecimento - para uma gramática moral dos conflitos sociais. Comunicação Pública, Especial 01E, 2011 